\author{
Military Technical College \\ Kobry El-Kobbah, \\ Cairo, Egypt
}

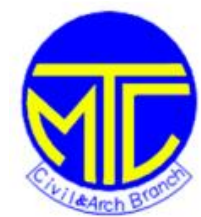

$9^{\text {th }}$ International Conference

on Civil and Architecture

Engineering ICCAE-9-2012

\title{
DETERMINATION OF WAT ER LEAKAGE AMOUNT BY RESIDUAL CHLORINE ME ASURING IN WATER PIPE NETWORK
}

\author{
A. N. Sakour*, M. E. El Nadi**, N. H. Amer*** and H. M. ElHanafy***
}

\section{Abstract:}

The objective of conducting this research is to find a relationship between leakage and chlorine added in terms of measured values of pressure, the length of pipe, age of the network and type of pipe for eight different zones in Cairo water supply network.

To achieve this goal, the measured values of water leakage, residual chlorine, pressure, length of pipes, age and type of pipe within the eight networks have been sorted out.

By using linear regression analysis, the equation that represents the relationship between the independent, (residual chlorine) and the dependents, has been obtained with acceptable error.

The application of the equation of Hazen-Williams was applied for taking the effect of p ipe type \& age using its friction coefficient on pipe length and then pipe diameter using the flow. Then the lengths were combined with all other data for each network, to get the relation between leakage and residual chlorine.

By applying the Program SSPS 10 for windows on the data determined from the field measurements from zones $1,2,3,5 \& 8$ it produces an equation simulate the leakage value relation with the residual chlorine taking into consideration the pipes diameter, length, age and type with the pressure loss in the studied networks. The produced equation verified with the field measurements from zones $4,6 \& 7$ and was successfully applicable with error less than $\pm 10 \%$.

\section{Keywords:}

Water leakage, residual chlorine

\section{Introduction:}

Leaks in pipe networks cause significant problems for utilities and water users in terms of lost revenue and interrupted service. In many cities the leakage is as high as forty percent. A water audit is carried out to assess system-wide leakage. However, to detect leakage at the level of a pipeline, a physical measurement technique is generally employed. For large cities the distribution piping length amounts to a few thousand miles.

In drinking water utilities, a strict control of residual chlorine levels is required during $t$ he treatment process and within the distribution system. Chlorine does applied during water treatment are in many cases adjusted manually according to the information on residual chlorine measured downstream from field sampling or on-line monitors.

\footnotetext{
* Syrian Arab Army

** Ain Shams University

*** Military Technical College
} 
The control of water quality, is important to estimate the evolution of water quality from the treatment plan to the consumers tap. During the water transportation through the distribution network, the residual chlorine concentration ensures microbiolog ically safe water quality. The residual chlorine concentration diminishes due to the reactions within the pipeline and outwardness from leakage in the pipe line.

Every water system in the world has a certain volume of real losses, and it is well known amon $g$ leakage practitioners that real losses cannot be eliminated completely, and even in newly commissioned distribution networks there is a minimum volume of real losses. However, it is also well known and proven that real losses can be managed so that they are within economic limits.

The problems associated with water loss are numerous. High real losses indirectly require water suppliers to extract, treat, and transport greater volumes of water than their customer demand requires. The additional energy neede $\mathrm{d}$ for treatment and transport taxes energy-generating capabilities which often rely upon large quantities of water in their process. Leaks, bursts, and overflows often cause considerable damage and inflate liability for the supplier. In order to find an easy and speedy way to knowledge leakage from water supply network and a little rate of keying error, this will be seen later in this research.

\section{Materials and methods:}

\subsection{Objectives}

The main objective of the current research is to find the direct relatio nship between the losses in water distribution networks and the residual chlorine. This is to use the residual chlorine to determine the leakage points and amounts in any water network.

\subsection{Scope of Work}

The study will be divided to two main types of work. The first is the practical work that made in the field. The field experimental program is designed to monitor the losses in water distribution networks and how it can be related to the residual chlorine in an eight zones of pipe network.

The second is the analytical work that made on computer including the collecting data from literature review and operators of existing networks. Also analyzing the field measurements through a mathematical metabolism for the measured data of residual chlorine, pressure, 1 ength of pipelines, age, type of material and water leakage to determine an equation. Simulate the relationship between them using the nearest standard equation to the curve obtained from the actual readings is also president.

\subsection{Chosen zones description}

Eight networks have been chosen for the study in different locations. One of the main reasons for selecting the eight locations, is that, the eight locations have different social and consequently different habits, so by its turn, it affect the water consu mption from one region to the another. Also, science Cairo - as the capital of Egypt - its network has been upgraded along different periods.

The eight locations are characterized by different factors. The selected locations are shown in the figures from figure (1) to figure (8) and as indicated these locations have different areas and different populations.

As mentioned before, the different habits, different jobs and consequently different working hours for the residents, affect the water consumptions.

In addition to the difference in the networks characteristics, this will be discussed in more lately. 

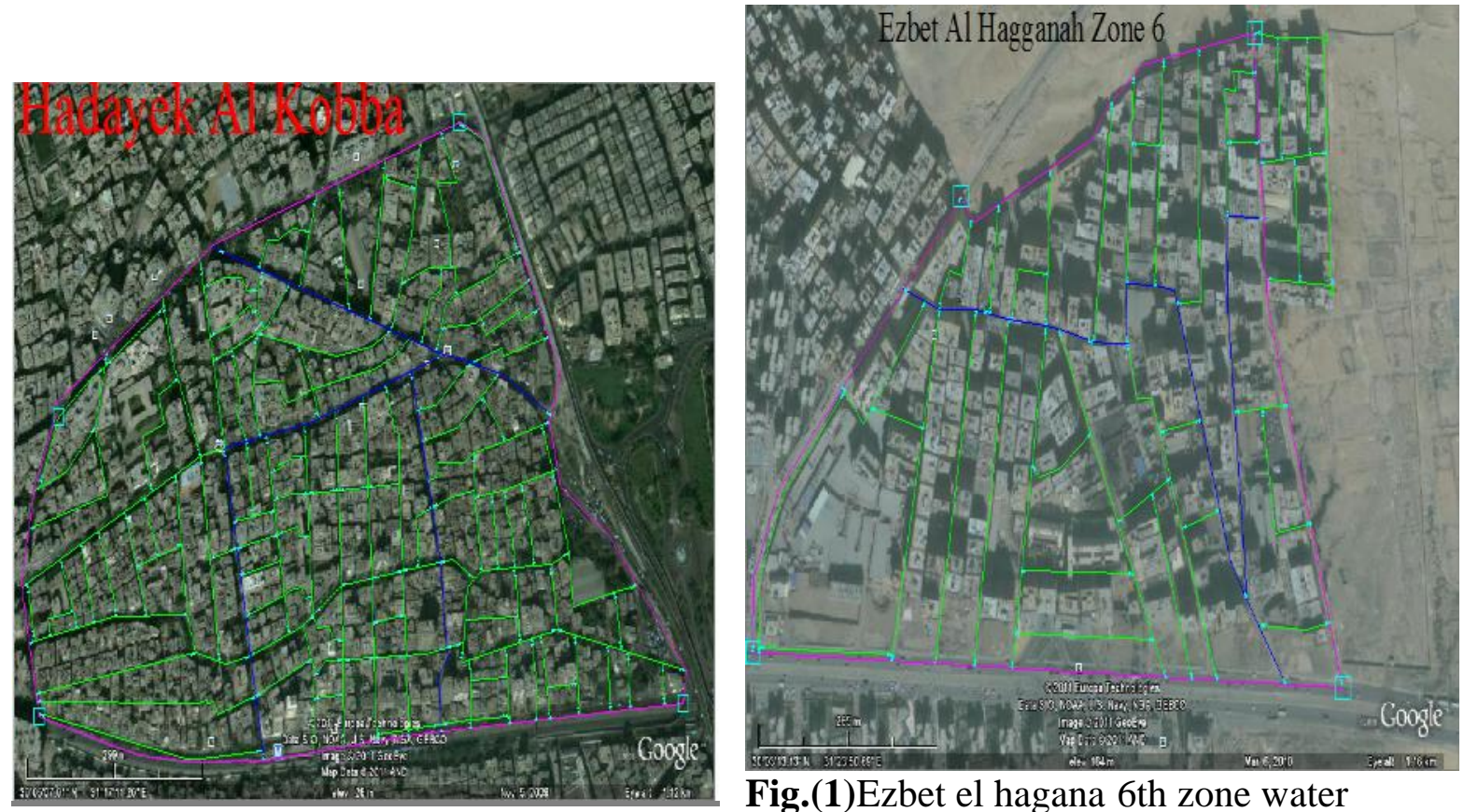

networks Fig.(2) Heliopolice hospital water network

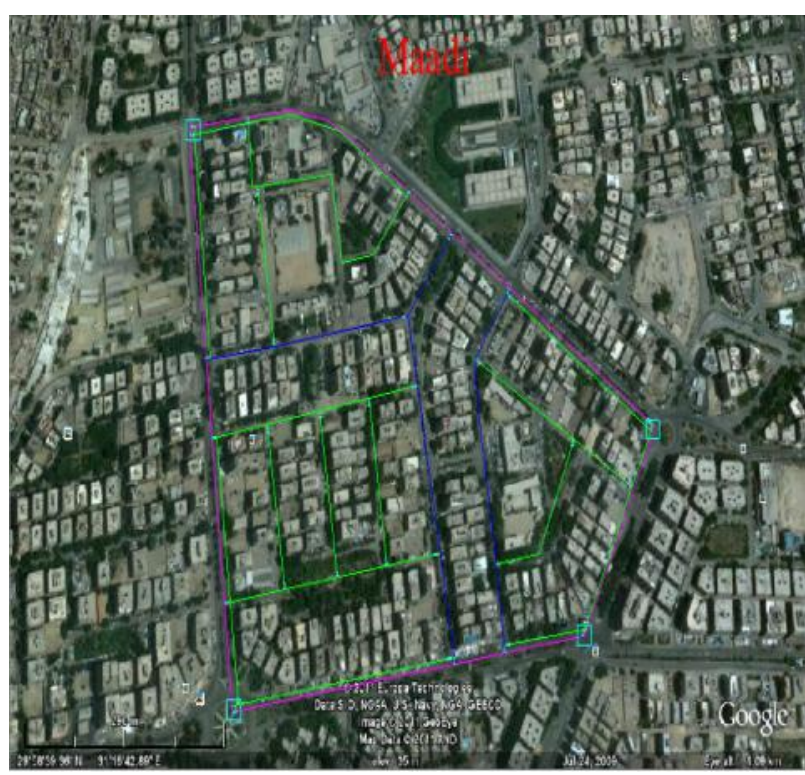

Fig.(3) Hadayek el koba water network

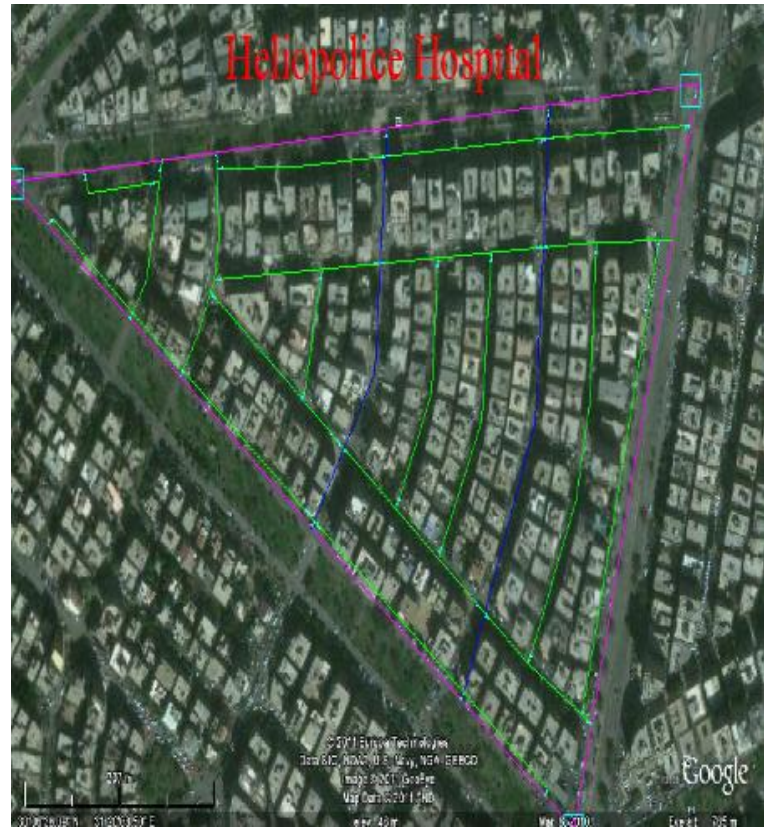

Fig.(4) Maadi water network 

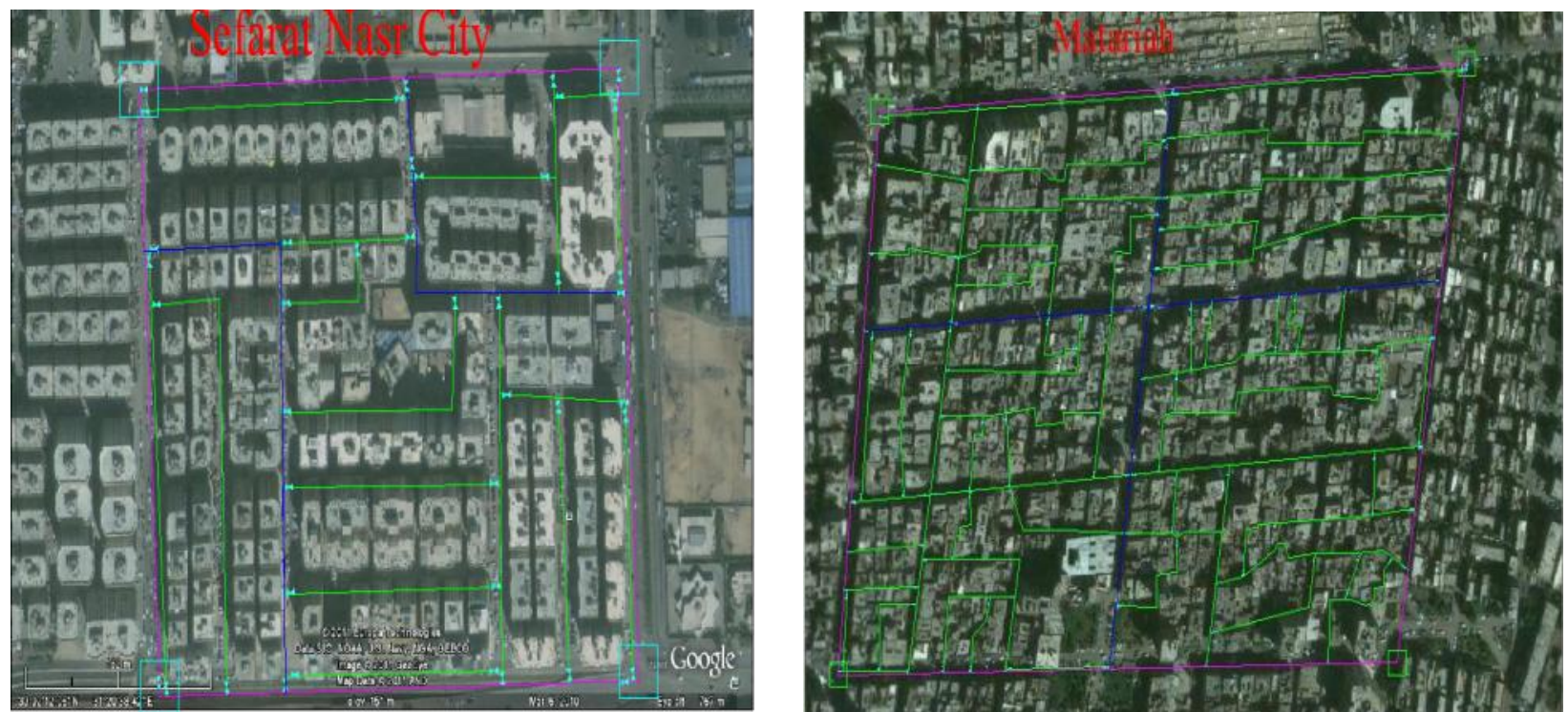

Fig.(5) madient el kodah nasr city water network
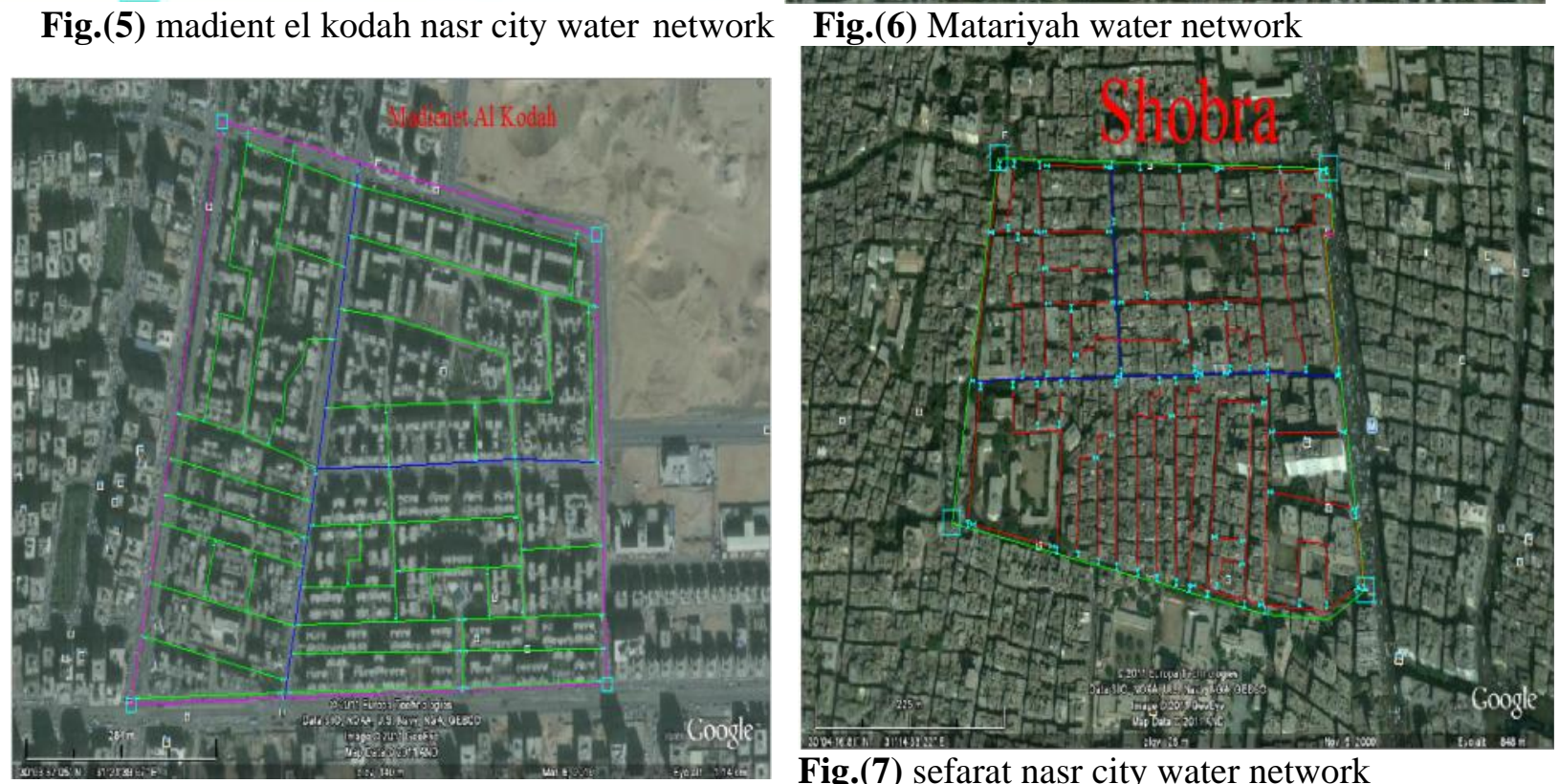

Fig.(7) sefarat nasr city water network

Fig.(8) Shobra water network

\subsection{Field program}

The eight networks in Cairo water network with different characteristics have been chosen as mentioned above. These characteristics should include types of pipe, diameter, length, age, and types of planning. The program of working in the eight zones is the same, and will be discussed in more details in the operation program. This program has been executed in series, i.e. all the program procedures are done for the first zone, then the second, and so on.

\section{Measured Results:}

At the inlet and outlet, the discharge, pressure and residual chlorine where measured while the house connections and fire hydrants are closed. The measured data are recorded in table (1). 
Table (1) The field measurements and equivalents values for all zones

\begin{tabular}{|c|c|c|c|c|c|c|c|}
\hline $\begin{array}{l}\mathrm{N}^{\circ} \\
\text { zone }\end{array}$ & $\begin{array}{l}\text { Time } \\
\text { (min.) }\end{array}$ & $\begin{array}{l}\text { Res.chl. } \\
(\mathrm{mg} / \mathrm{l})\end{array}$ & $\begin{array}{l}\text { Pressure } \\
\text { (bar) }\end{array}$ & $\begin{array}{l}\text { Leakage } \\
\text { (Q2-Q1) } \\
\text { 1/s }\end{array}$ & $\begin{array}{l}\text { Length } \\
\text { (m) }\end{array}$ & $\begin{array}{l}\text { Age } \\
\text { (year) }\end{array}$ & $\begin{array}{l}\text { Friction } \\
\text { coefficient (C } \\
\text { ) of pipe }\end{array}$ \\
\hline \multirow[t]{6}{*}{1} & 0 & 0.4 & 3 & 0 & 9553 & 0.25 & 150 \\
\hline & 10 & 0.37 & 2.9 & 0.25 & 9553 & 0.25 & 150 \\
\hline & 20 & 0.34 & 2.8 & 0.5 & 9553 & 0.25 & 150 \\
\hline & 40 & 0.3 & 2.7 & 0.9 & 9553 & 0.25 & 150 \\
\hline & 60 & 0.255 & 2.5 & 1.4 & 9553 & 0.25 & 150 \\
\hline & 80 & 0.1975 & 2.3 & 1.95 & 9553 & 0.25 & 150 \\
\hline \multirow[t]{6}{*}{2} & 0 & 0.4 & 3.4 & 0 & 23111 & 40 & 140 \\
\hline & 10 & 0.39 & 3.3 & 0.1 & 23111 & 40 & 140 \\
\hline & 20 & 0.375 & 3.2 & 0.2 & 23111 & 40 & 140 \\
\hline & 40 & 0.35 & 3.1 & 0.4 & 23111 & 40 & 140 \\
\hline & 60 & 0.315 & 3 & 0.6 & 23111 & 40 & 140 \\
\hline & 80 & 0.2825 & 2.9 & 0.9 & 23111 & 40 & 140 \\
\hline \multirow[t]{6}{*}{3} & 0 & 0.4 & 2.9 & 0 & 4924 & 60 & 120 \\
\hline & 10 & 0.39 & 2.8 & 0.1 & 4924 & 60 & 120 \\
\hline & 20 & 0.37 & 2.725 & 0.2 & 4924 & 60 & 120 \\
\hline & 40 & 0.34 & 2.675 & 0.4 & 4924 & 60 & 120 \\
\hline & 60 & 0.31 & 2.6 & 0.6 & 4924 & 60 & 120 \\
\hline & 80 & 0.275 & 2.475 & 0.9 & 4924 & 60 & 120 \\
\hline \multirow[t]{6}{*}{4} & 0 & 0.4 & 2.9 & 0 & 6999 & 15 & 150 \\
\hline & 10 & 0.39 & 2.8 & 0.1 & 6999 & 15 & 150 \\
\hline & 20 & 0.3775 & 2.725 & 0.2 & 6999 & 15 & 150 \\
\hline & 40 & 0.36 & 2.675 & 0.4 & 6999 & 15 & 150 \\
\hline & 60 & 0.3425 & 2.6 & 0.6 & 6999 & 15 & 150 \\
\hline & 80 & 0.3225 & 2.475 & 0.9 & 6999 & 15 & 150 \\
\hline \multirow[t]{6}{*}{5} & 0 & 0.4 & 2.5 & 0 & 8353 & 80 & 130 \\
\hline & 10 & 0.3825 & 2.4 & 0.1 & 8353 & 80 & 130 \\
\hline & 20 & 0.3575 & 2.3 & 0.2 & 8353 & 80 & 130 \\
\hline & 40 & 0.3175 & 2.2 & 0.4 & 8353 & 80 & 130 \\
\hline & 60 & 0.2775 & 2.1 & 0.6 & 8353 & 80 & 130 \\
\hline & 80 & 0.24 & 2 & 0.9 & 8353 & 80 & 130 \\
\hline \multirow[t]{6}{*}{6} & 0 & 0.4 & 3.5 & 0 & 10084 & 20 & 150 \\
\hline & 10 & 0.39 & 3.4 & 0.1 & 10084 & 20 & 150 \\
\hline & 20 & 0.3775 & 3.3 & 0.2 & 10084 & 20 & 150 \\
\hline & 40 & 0.36 & 3.2 & 0.4 & 10084 & 20 & 150 \\
\hline & 60 & 0.3425 & 3.1 & 0.6 & 10084 & 20 & 150 \\
\hline & 80 & 0.3225 & 3 & 0.9 & 10084 & 20 & 150 \\
\hline \multirow[t]{6}{*}{7} & 0 & 0.4 & 3.5 & 0 & 5327 & 10 & 150 \\
\hline & 10 & 0.39 & 3.4 & 0.1 & 5327 & 10 & 150 \\
\hline & 20 & 0.3775 & 3.3 & 0.2 & 5327 & 10 & 150 \\
\hline & 40 & 0.36 & 3.2 & 0.4 & 5327 & 10 & 150 \\
\hline & 60 & 0.3425 & 3.1 & 0.6 & 5327 & 10 & 150 \\
\hline & 80 & 0.3225 & 3 & 0.9 & 5327 & 10 & 150 \\
\hline \multirow[t]{2}{*}{8} & 0 & 0.4 & 3.5 & 0 & 7347 & 75 & 140 \\
\hline & 10 & 0.39 & 3.4 & 0.1 & 7347 & 75 & 140 \\
\hline
\end{tabular}




\begin{tabular}{|l|l|l|l|l|l|l|l|}
\hline \multirow{7}{*}{} & 20 & 0.3775 & 3.3 & 0.2 & 7347 & 75 & 140 \\
\cline { 2 - 8 } & 40 & 0.36 & 3.2 & 0.4 & 7347 & 75 & 140 \\
\cline { 2 - 8 } & 60 & 0.3425 & 3.1 & 0.6 & 7347 & 75 & 140 \\
\cline { 2 - 8 } & 80 & 0.3225 & 3 & 0.9 & 7347 & 75 & 140 \\
\hline
\end{tabular}

\section{Discussion of Field Results:}

\subsection{Producing of the mathematical model}

To solve several variables together it is difficult to use simplified methods as Excel of Microsoft for the accuracy and the division will be high. Thi s lead to find a sophisticated program to solve or obtain a suitable equation with these several variables a program called (SPSS 10 for windows) was found and applied to get the required relation for all the items with acceptable margin of error.

By applying the Program SSPS 10 for windows on the data determined from the field measurements from zones $1,2,3,5 \& 8$ it produces an equation could simulate the leakage value relation with the residual chlorine taking into consideration the pipes diameter, length, age and type with the pressure loss in the studied networks.

The produced equation can be presented as follows:

Ch= 0.284+ 3.456.10-2 P- 0.103 Q -1.00.10-6 L-1.52.10-4 A+1.907.10-4 C

Where:

$$
\begin{aligned}
\mathrm{R}^{2} & =0.951 . \\
\mathrm{Q} & =\text { leakage in pipelines }(1 / \mathrm{s}) \\
\mathrm{Ch} & =\text { Residual chlorine }(\mathrm{mg} / \mathrm{l}) \\
\mathrm{P} & =\text { Pressure in pipelines (bar) } \\
\mathrm{L} & =\text { Length of pipelines }(\mathrm{m}) \\
\mathrm{C} & =\text { Hazen }- \text { Williams coefficient for material type of pipe } \\
\mathrm{A} & =\text { Age of pipeline network (year) }
\end{aligned}
$$

\subsection{Equation verification}

The equation obtained from the five zones mentioned previously and the verification of equation is applied on the five zones and the other three zones.

\subsubsection{Equation verification on the same five zones}

\begin{tabular}{|c|c|c|c|c|}
\hline \multirow[t]{2}{*}{ Zone } & \multirow{2}{*}{$\begin{array}{l}\text { Time } \\
\text { (minutes) }\end{array}$} & \multicolumn{2}{|c|}{ Residual chlorine(mg/l) } & \multirow{2}{*}{$\begin{array}{l}\text { Deviation } \\
\text { percent } \\
(\%)\end{array}$} \\
\hline & & $\begin{array}{l}\text { From field } \\
\text { measures }\end{array}$ & $\begin{array}{l}\text { From equation } \\
\text { results }\end{array}$ & \\
\hline \multirow[t]{6}{*}{1} & 0 & 0.4 & 0.4 & 0 \\
\hline & 10 & 0.37 & 0.37 & 0 \\
\hline & 20 & 0.34 & 0.34 & 0 \\
\hline & 40 & 0.3 & 0.3 & 0 \\
\hline & 60 & 0.255 & 0.243 & 4.7 \\
\hline & 80 & 0.1975 & 0.18 & 8.86 \\
\hline \multirow[t]{3}{*}{2} & 0 & 0.4 & 0.4 & 0 \\
\hline & 10 & 0.39 & 0.385 & 0 \\
\hline & 20 & 0.375 & 0.3715 & 1.28 \\
\hline
\end{tabular}

The residual chlorine obtained from field measurements are compared with calculated from equation (1) according to the time and then calculate the percent deviation for the field measurements and the equation results. Table (2) shows the variation of residual chlorine for five zones. Figures $(1,2,3,4 \& 5)$ show Comparison of the residual chlorine from field results and from equation with time in five zones.

Table (2) Variation of residual chlorine from field and eq uation for zones $(1,2,3,5 \& 8)$ 


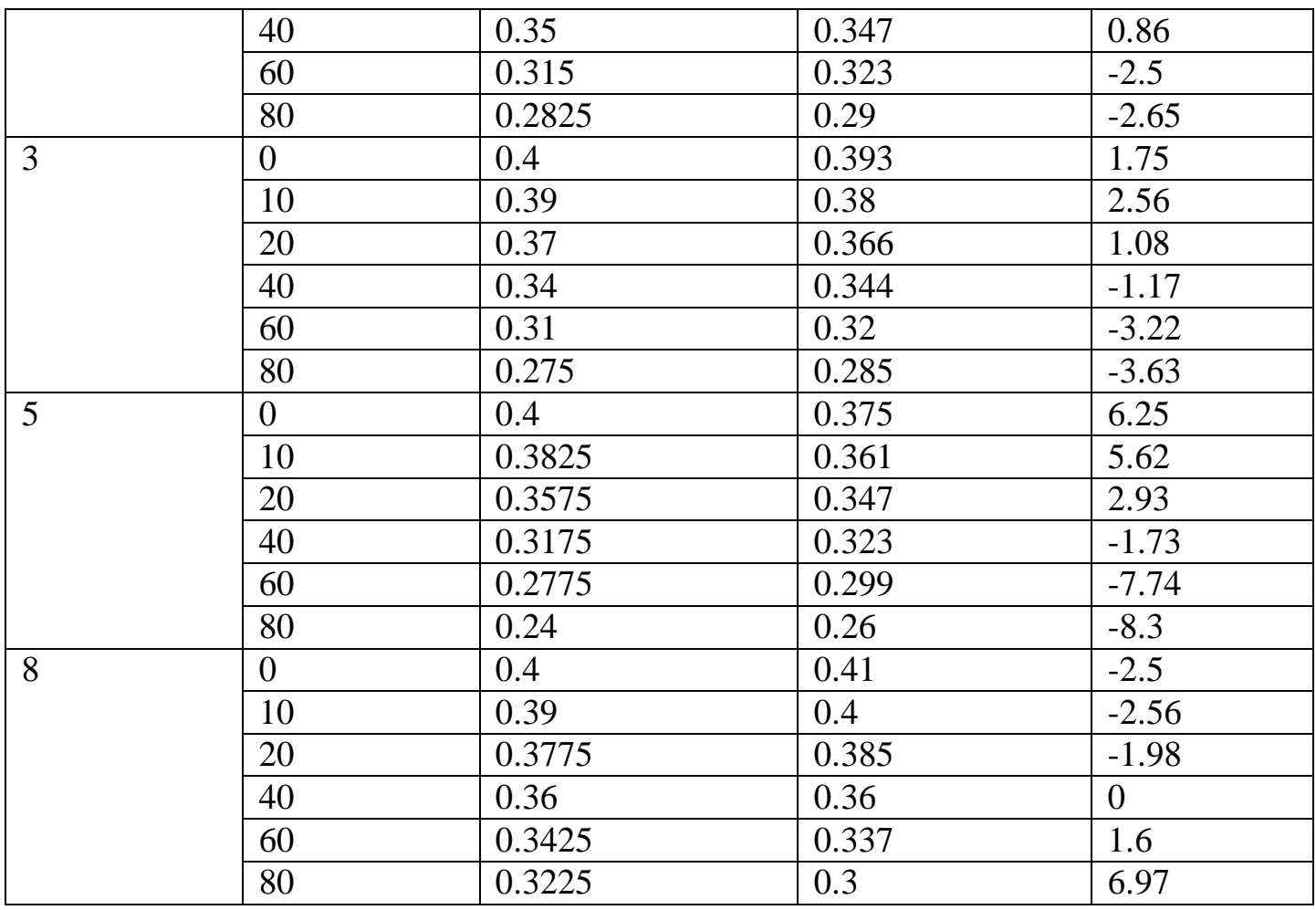

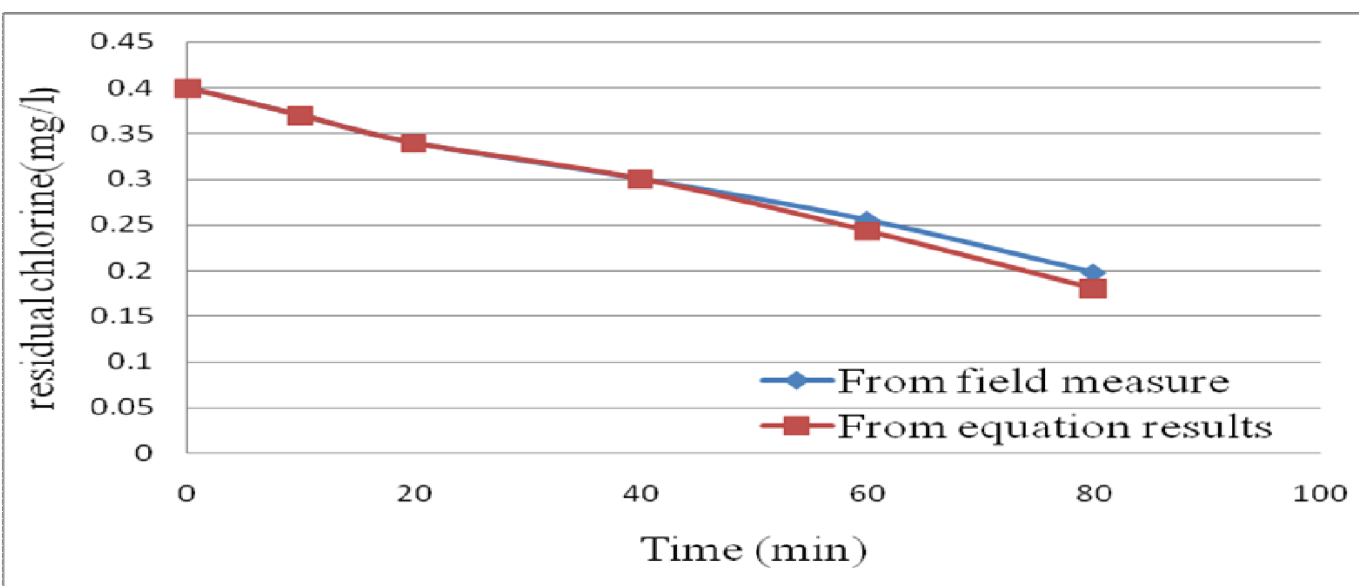

Fig.(1)Comparison between residual chlorine results from field and equation in zone (1)

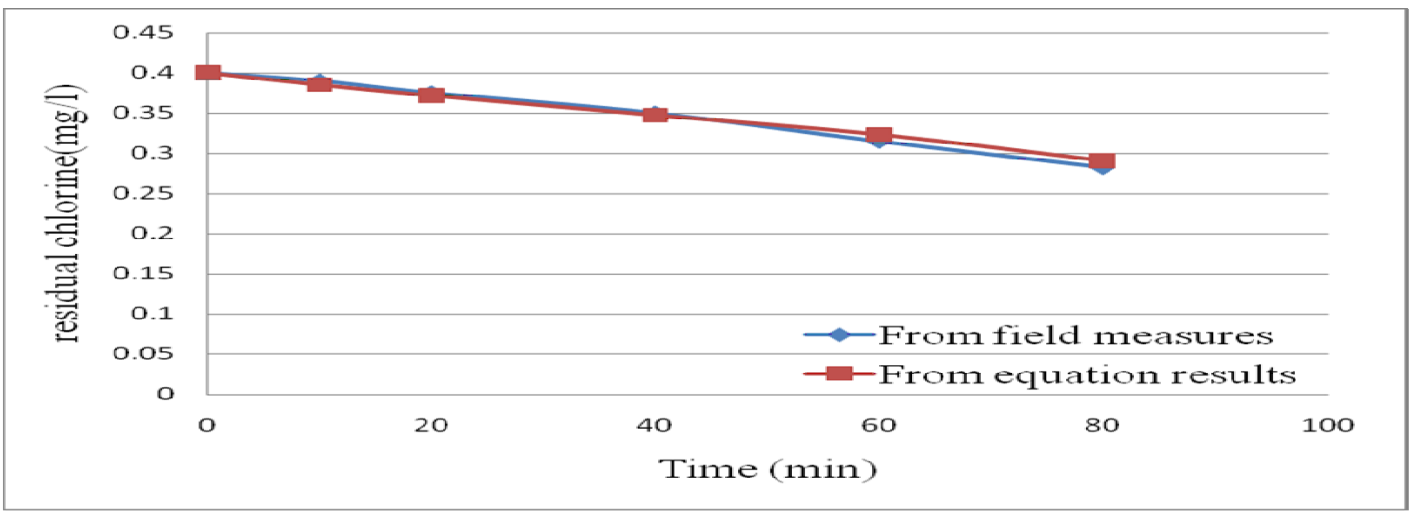

Fig.(2)Comparison between residual chlorine results from field and equation in zone (2) 


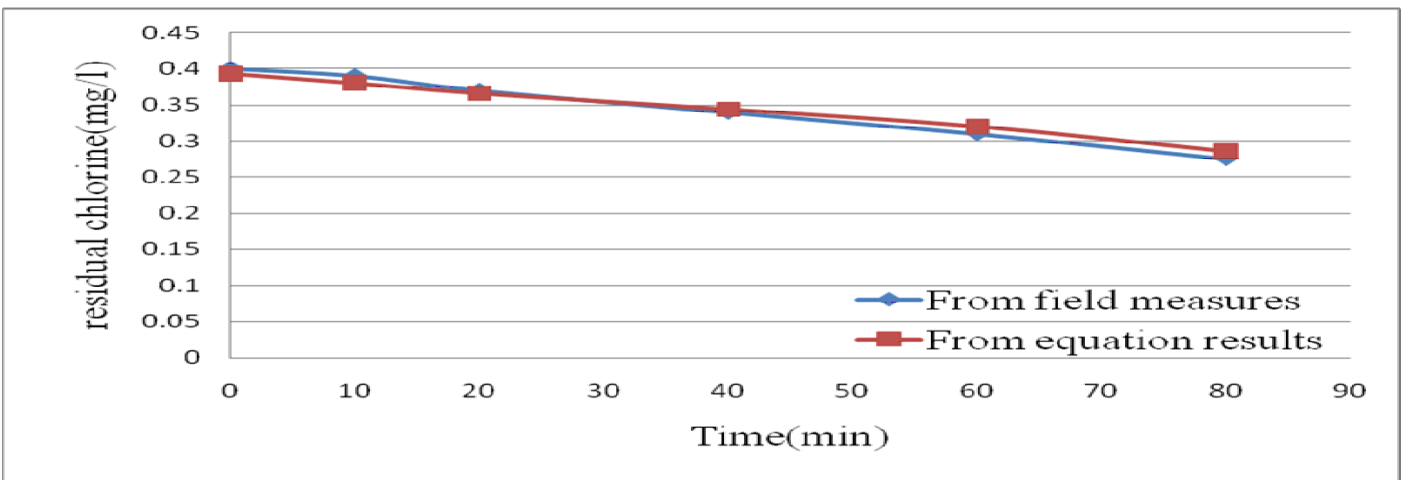

Fig.(3)Comparison between residual chlorine results from field and equation in $\mathrm{z}$ one (3)

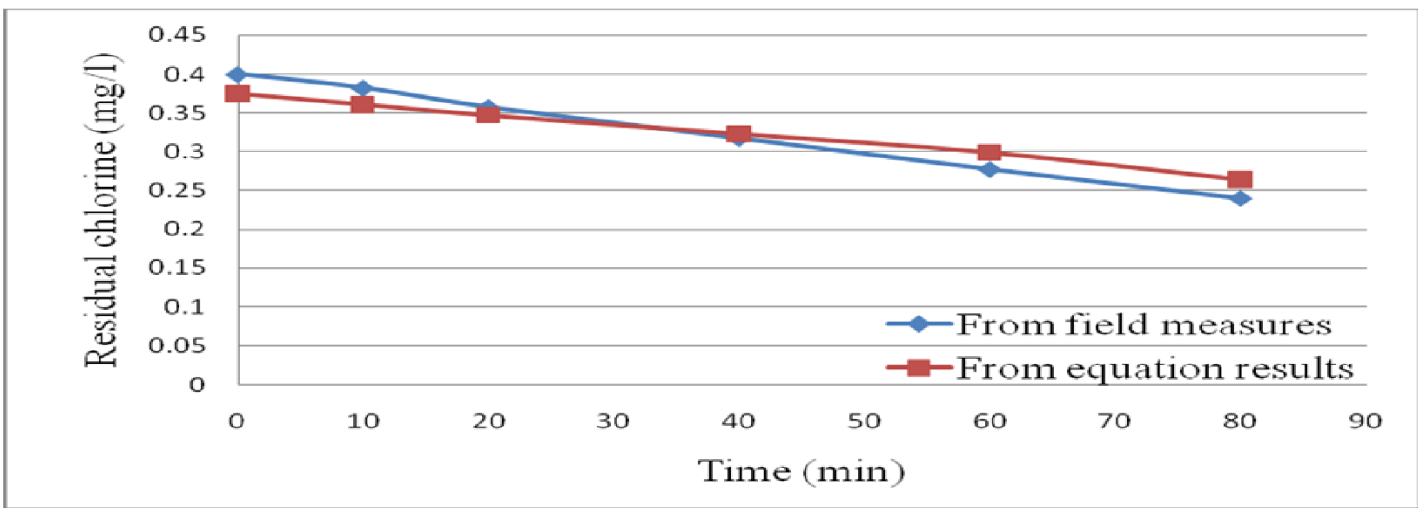

Fig.(4)Comparison between residual chlorine results from field and equation in zone (5)

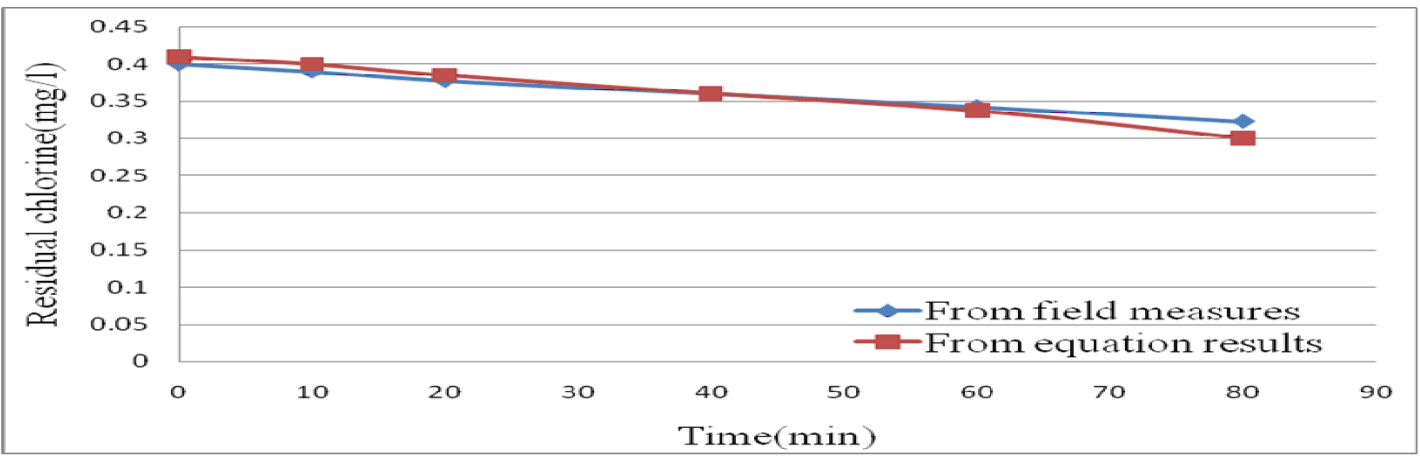

Fig.(5)Comparison between residual chlorine results from field and equation in zone (8)

The results show that the deviation percent between field measuremen ts and the equation results is ranged from $(-8.3)$ to $(+8.86) \%$. It is acceptable result, because the error does not exceed the acceptable range $\pm 10 \%$.

\subsubsection{Equation verification on other three zones}

The residual chlorine obtained from field measurements ar e compared with calculated from equation (1) according to the time and then calculate the percent deviation for the field measurements and the equation results. Table (3) shows the variation of residual chlorine for three zones $4,6 \& 7$. Figures $(6,7 \& 8)$ show Comparison of the residual chlorine from field results and from equation with time in three zones.

Table (3) Variation of residual chlorine from field and equation for zones (4, 6 \& 7)

\begin{tabular}{|l|l|l|l|l|}
\hline Zone & Time & Residual chlorine $(\mathrm{mg} / \mathrm{l})$ & Deviation \\
& (minutes $)$ & From field measures & From equation results & Percent $(\%)$ \\
\hline 4 & 0 & 0.40 & 0.40 & 0 \\
\hline
\end{tabular}




\begin{tabular}{|l|l|l|l|l|}
\hline \multirow{5}{*}{} & 10 & 0.39 & 0.39 & 0 \\
\cline { 2 - 5 } & 20 & 0.3775 & 0.377 & 0.13 \\
\cline { 2 - 5 } & 40 & 0.36 & 0.3546 & 1.5 \\
\cline { 2 - 5 } & 60 & 0.3425 & 0.331 & 3.35 \\
\cline { 2 - 5 } & 80 & 0.3225 & 0.2962 & 8.15 \\
\hline 6 & 0 & 0.40 & 0.42 & -5 \\
\cline { 2 - 5 } & 10 & 0.39 & 0.40 & -2.63 \\
\cline { 2 - 5 } & 20 & 0.3775 & 0.39 & -3.31 \\
\cline { 2 - 5 } & 40 & 0.36 & 0.368 & -2.22 \\
\cline { 2 - 5 } & 60 & 0.3425 & 0.3445 & -0.58 \\
\cline { 2 - 5 } & 80 & 0.3225 & 0.31 & 3.87 \\
\hline 7 & 0 & 0.4 & 0.42 & -5 \\
\cline { 2 - 5 } & 10 & 0.39 & 0.41 & -5.12 \\
\cline { 2 - 5 } & 20 & 0.3775 & 0.399 & -4.69 \\
\cline { 2 - 5 } & 40 & 0.36 & 0.375 & -2.48 \\
\cline { 2 - 5 } & 60 & 0.3425 & 0.351 & 1.7 \\
\cline { 2 - 5 } & 80 & 0.3225 & 0.317 & \\
\hline
\end{tabular}

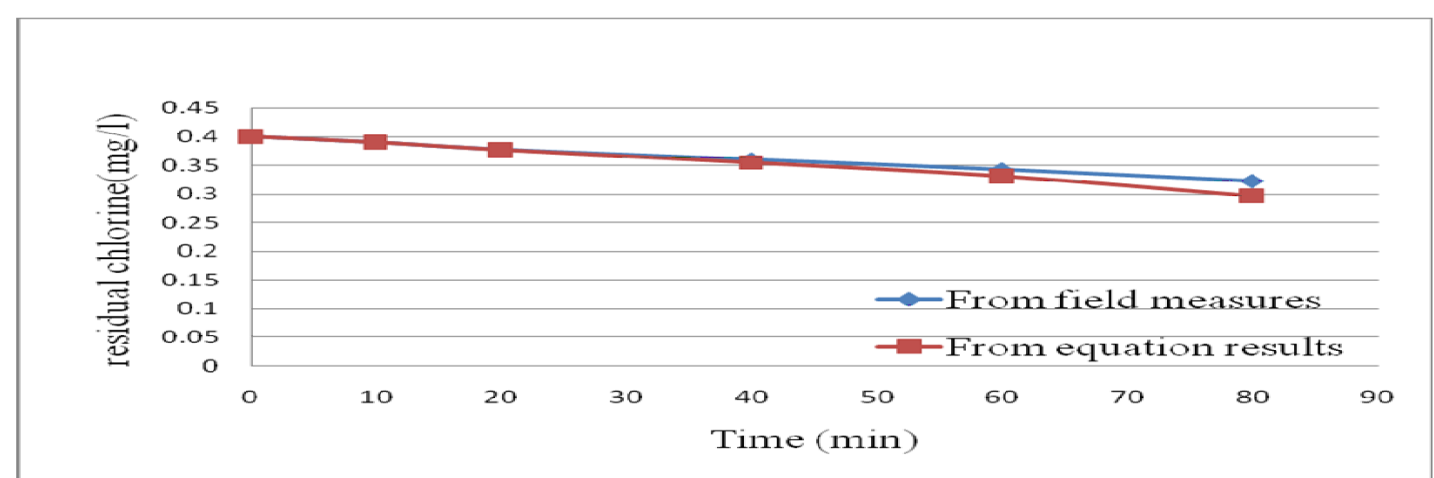

Fig.(6)Comparison between residual chlorine results from field and equation in zone (4)

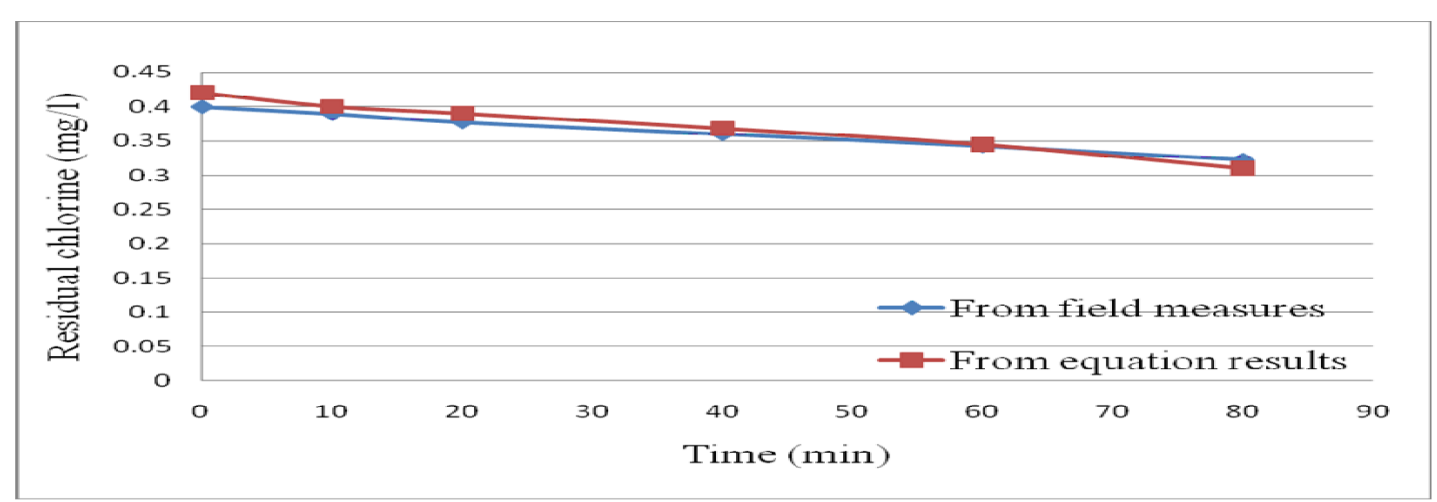

Fig.(7)Comparison between residual chlorine results from field and equation in zone (6). 


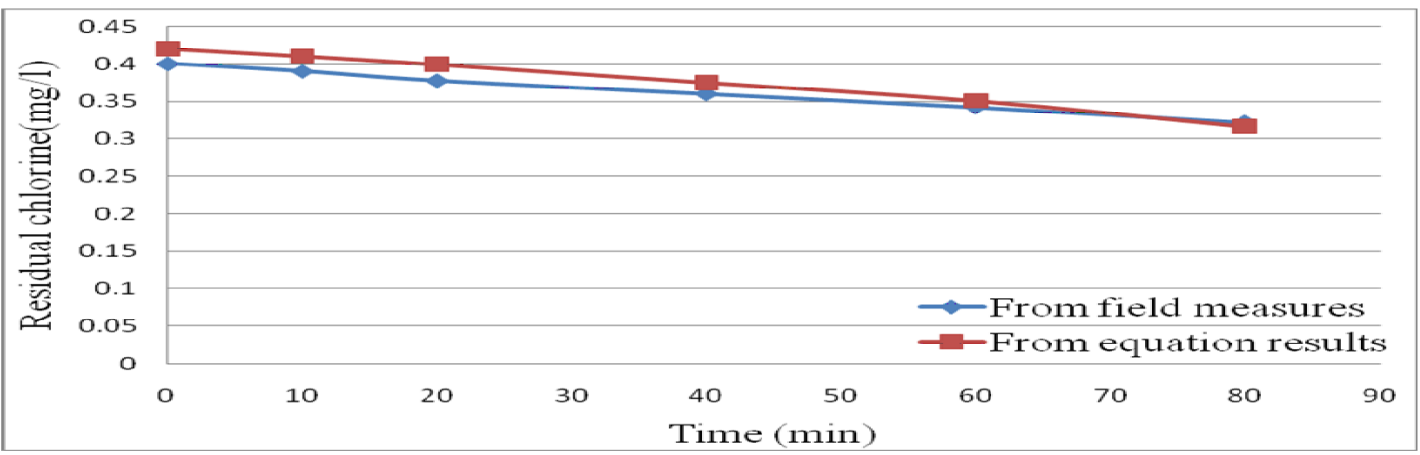

Fig.(8)Comparison between residual chlorine results from field and equation in zone (7).

The results show that the deviation percent between field mea surements and the equation results is ranged from $(-5.69)$ to $(8.15) \%$. It is acceptable result because of the error does not exceed the permissible range of $\pm 10 \%$.

\subsubsection{Verification results}

The results show that the percent deviation does not exceed the ac ceptable range of $\pm 10 \%$. So, the equation simulates any pipe network to be used to find the relationship between the residual chlorine, leakage, pressure, length of the pipelines, age of pipe and type of pipe with very small acceptable deviation.

Finally we can say that the equation obtained is stable and reflect all components of the network and their relationship.

\section{Conclusions}

Throughout our work presented in this paper, the following conclusions are extracted:

1. The pipe properties as type (friction coe fficient), sizing (diameter), age \& length are affected the leakage amount.

2. The flow and pressure are the main affecting parameters for leakage amount.

3. The relation between residual chlorine and the leakage amount are proportional and very noticeable.

4. The produced equation for the relationship between residual chlorine, pressure, pipe length, age and type of material are illustrated here after.

Ch= 0.284+ 3.456.10-2 P- 0.103 Q-1.00.10-6 L-1.52.10-4 A+1.907.10-4 C

Where:

$R^{2} \quad=0.951$.

$Q \quad=$ leakage in pipelines $(l / s)$

Ch = Residual chlorine $(\mathrm{mg} / \mathrm{l})$

$P \quad=$ Pressure in pipelines (bar)

$L \quad=$ Length of pipelines $(m)$

C = Hazen-Williams coefficient for material type of pipe

$A \quad=$ Age of pipeline network (year)

This is a simplified and easy methodology to determine l eakage amount and location that ease the controlling of pipe networks

\section{References}

1. Kristin Brown, "Modeling Leakage in Water Distribution Systems", The Florida State University, 2007.

2. Colombo A., Karney B.,'Energy and Costs of Leaky Pipes", Journ al of Water Resources Planning and Management. p441- 450, 2002. 
3. American Water Works Association (AWWA),"Apparent and Real Losses", 2006.

4. Stathis J., Loganathan G.V.," Analysis of Pressure Dependent Leakage in Water Distribution Systems", Preparing for the 21st Century: Water Resources Planning and Management Conference 1999.

5. Black \& Veatch," A Technical Analysis of the Energy Resource", American Wind Energy Association, October, 2007.

6. Manual of Water Supply Practices AWWA,"Water Audits and Leak Detection", ISBN 0 89867485 0, M36, 1990.

7. Hirner W.H., "Unaccounted-for Water", Conference on Water Utility Partnership for Capacity Building, Kampala, Uganda. October, 1997.

8. Lambert A., Myers S., Trow S.,"Managing Water Leakage, Published by Financial T imes Energy", London, 1998.

9. Lahlou, Zacharia M.," Leak detection and water loss control", West Virginia University, 2001.

10. US Army Corps of Engineers (USACE), "Leak Detection", Public Works Technical Bulletin 420-49-36, Washington, 2001.

11. San Jose, "Sub Surface Leak Detection", LC-2500 leak noise correlator, California, 2006.

12. Parrott, Ralph W., H.L. Thornton.," Proprietary Tracer Gas Hydro -test leak Detection System", Pipeline and Gas Journal, March, 2003.

13. Zhao,J.Q., "Slipline rehabilitation of water mains wi th high-density polyethylene pipe", Construction Technology Update No. 56, Jan, 2003. 